\section{Sport and exercise medicine: served three ways}

\author{
Eleanor Tillett
}

Welcome to the 2018 British Association of Sport \& Exercise Medicine (BASEM) issue of the British Journal of Sports Medicine (BJSM). It is always a pleasure to bring this issue together; both due to the plethora of high quality articles to choose from and the opportunity to report the positive changes that continue within BASEM.

\section{BACK TO THE FUTURE}

At our AGM in 2017 our membership voted that we should go back to our roots and once again become a truly multi-disciplinary organisation. BASEM now gives all full members, whatever the type of Sports and Exercise Medicine (SEM) practitioner, equal access and rights to all that BASEM has to offer. This is a very positive stride towards collaboration and development across all SEM communities and we are looking forward to this next exciting phase. It seems collaboration is in the air internationally too with David Humphries and an international author team (see page 490) reporting on the first stage of an International Syllabus in Sport and Exercise Medicine.

BASEM and The Faculty of Sport and Exercise Medicine's annual conference will be at The Royal Armouries in Leeds this year; it's a great centre geographically and the conference brings together clinical and academic excellence. We are, very gently, expanding the conference this year to serve the breadth of our membership. There will be three streams; one focusing on musculoskeletal medicine, another on exercise medicine, and a third on team care... 'Sport and Exercise Medicine - Served Three Ways'. To mirror the conference format, this issue also balances these three areas.

\section{STARTER: EXERCISE MEDICINE}

This course is quite rightly led by Dr Charlie Foster and colleagues with an editorial (see page 484) on the WHO's global action plan to promote physical activity. The combination of health and sustainability targets makes this call to action key and I urge you to explore the linked resources from this article. To accompany this editorial, three

Correspondence to Dr Eleanor Tillett, Division of Surgery and Interventional Science, University College London, London WC1E 6BT, UK; e.tillett@ucl.ac.uk

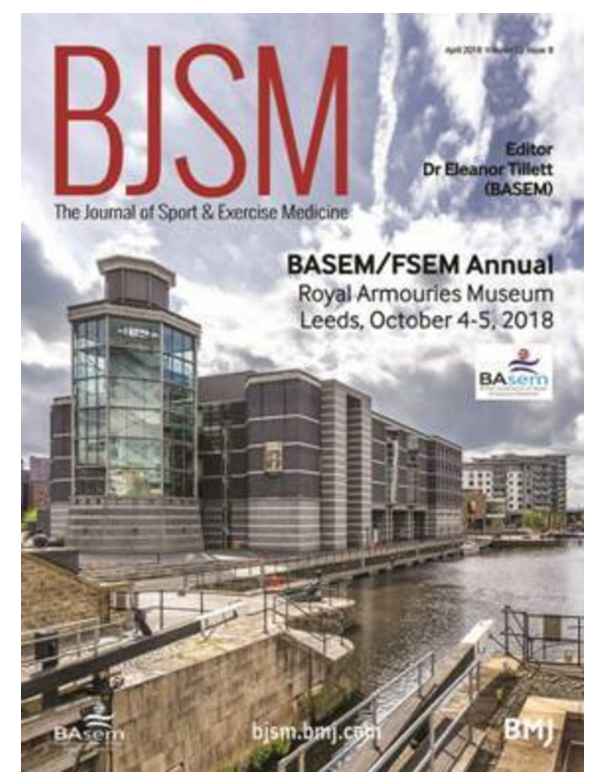

had had $>1$ year duration of symptoms, (ii) in the presence of radiological knee osteoarthritis, and (iii) when $>50 \%$ of the meniscus had been resected. This review will help to support our discussions with patients in clinic, but with the evidence for other predictors being less clear, the importance of applying clinical decision-making skills to the individual patient will remain key.

\section{AND FOR DESSERT: TEAM CARE}

Tim Gabbett produced a concise guide to working in elite sport - see the infographic on 'Developing and maintaining a high performance sports medicine team'. Read Jan Ekstrand's (see page 527) novel perspective on injury risk in team sports examining the correlation between coaches' leadership style and injuries in elite football teams. What they've found could lead to some interesting discussions with certain football managers!

Alongside team dynamics there is also a study exploring different vitamin D assays and their association with bone mineral density (see page 522) and an editorial highlighting the need to develop a better understanding of gastrointestinal symptoms in athletes (see page 487).

papers report specific challenges within physical activity. Christian Swann (see page 485) explores the role of goal setting and suggests we need to rethink its usefulness 'for individuals at the early stages of learning to be active'. In addition, there are reviews on the roles of physical activity during and after cancer treatment (see page 505) and also in chronic fatigue (see page 540).

\section{MAIN COURSE: MUSCULOSKELETAL MEDICINE}

For your MSK course we are serving a platter of joints and pathologies. There are a couple of dips into low back pain with Canada's Gilat Grunau (see page 488) challenging the role of red flags, and a review of a low back pain exercise app (see page 536).

The role, or not, of corticosteroid comes under scrutiny again in Duke University's Professor Chad Cook review (see page 493) of rotator cuff pathologies. May a change in practice be around the corner for this condition? The jury is out at this stage but it once again highlights the need to better understand pain drivers in all MSK pathology. Less surprising perhaps, is Susanne Eijgenraam's review (see page 514) of the outcome of arthroscopic partial meniscectomy. Poorer clinical outcomes were reported when one of 3 clinical settings was present: (i) when the patient

\section{COFFEE ANYONE?}

And if these articles aren't enough to satisfy your educational appetite then check out Ralph Smith's pregnancy infographic (see page 532) and Simon Lack's PhD BJSM interaction between hip and foot biomechanics in the presentation and management of patellofemoral knee pain'.

This issue will spark your own ideas for translating research into practice or even using one of these articles as a springboard for your own research. Last year's conference prize-winning abstracts are published. Follow BASEM's home page or social media accounts for information on how to submit your research gems for 2018. See you in Leeds on the fourth and fifth of October!

\section{Competing interests None declared.}

Provenance and peer review Commissioned; internally peer reviewed.

Data sharing statement Not applicable.

(C) Article author(s) (or their employer(s) unless otherwise stated in the text of the article) 2018. All rights reserved. No commercial use is permitted unless otherwise expressly granted.

$$
\text { D Check for updates }
$$

To cite Tillett E. Br J Sports Med 2018;52:483.

Br J Sports Med 2018;52:483.

doi:10.1136/bjsports-2018-099087 Academy Award (see page 542) on 'The 